\title{
Humic Acid Interferes with Species Recognition in Zebrafish (Danio rerio)
}

\author{
Niora J. Fabian ${ }^{1 \rrbracket}$, Lindsey B. Albright ${ }^{1}$, Gabriele Gerlach ${ }^{2}$, Heidi S. Fisher ${ }^{1}$ \\ and Gil G. Rosenthal ${ }^{3}$
}

(1) Department of Biology, Boston University, 5 Cummington St., Boston, MA 02215, USA

(2) Marine Biological Laboratory, Woods Hole, MA 02543, USA

(3) Texas A\&M University, 3258 TAMU, College Station, TX 77843, USA

$\checkmark$ Niora J. Fabian

Email: niora.fabian@gmail.com

Published online: 19 October 2007

\begin{abstract}
Few studies have addressed how chemosensation may be impaired by chemical alterations of the environment and anthropogenic disturbance. Humic acid (HA) is a pervasive, naturally occurring organic derivative found in aquatic and terrestrial environments; human activity, however, can lead to elevated levels of HA. Recent studies suggest that environments that contain high levels of HA may hinder chemical communication. We tested the ability of adult zebrafish (Danio rerio) to discriminate between conspecific and heterospecific urinary chemical cues found in the presence and absence of HA. We show that high humic acid levels (200 mg/l) can impair the ability to differentiate conspecifics from heterospecifics. We also found that zebrafish prefer untreated water over HA-treated water. These findings suggest that, in addition to human-produced synthetic compounds, changes in the abundance of naturally occurring substances may also negatively impact natural behaviors in aquatic species by disturbing the sensory environment.
\end{abstract}

Keywords Pheromones - Contamination - Mate choice - Chemical cues Cyprinidae

\section{Introduction}

Many aquatic animals have evolved mechanisms to send and receive information via chemical cues, and chemosensation plays a critical role in their behavior (Moore and Grills 1999; Atema et al. 2002; Russell et al. 2004; Rosenthal and Lobel 2006). Disruption of the sensory environment can impair communication, resulting in biological effects for many species (e.g., Seehhausen et al. 1997; Slabbekoorn and Peet 2003). Chemical recognition may be impaired by direct anthropogenic disturbances. For example, Wolf and Moore (2002) found that exposure to the pesticide metolachlor rendered crayfish unable to detect food 
sources and also elicited inappropriate behavior to other chemicals that could jeopardize their survival. Human impact can also alter the concentration of naturally occurring substances, which may additionally impair chemical recognition. This study examines the potential effect of the naturally occurring substance humic acid (HA). HA is a by-product of degrading organic matter and is increased by processes such as eutrophication (Thomas 1997).

Dissolved organic matter and humic substances constitute the majority of dead organic matter (Steinberg and Münster 1985; Thomas and Eaton 1996; Thomas 1997; Wetzel 2001). HA is a ubiquitous, naturally occurring organic component in aquatic environments associated with agricultural manure and other organic wastes (Atiyeh et al. 2002; Kappler and Haderlein 2003). Elevated levels of HA in aquatic habitats are of particular interest because of their apparent effect in impairing the recognition of conspecific sexual pheromones (Hubbard et al. 2002; Fisher et al. 2006). Mesquita et al. (2003) found that humic acids adsorb relatively water-insoluble organic substances such as steroidal pheromones, reducing their biological availability to organisms that normally detect these chemicals as part of their communication. Hubbard et al. (2002) proposed that the steroids adsorb onto the surface of humic acid microvesicles that form in water, rendering the pheromone effectively unavailable for olfactory detection by Carassius auratus and other teleosts in natural environments.

Female swordtail fish (Xiphophorus birchmanni) lose their preference for conspecific males over heterospecific males in water with elevated levels of HA (Fisher et al. 2006). This impairment of chemical communication may have implications for the evolutionary fate of many species because of the potential for interspecific hybridization.

The zebrafish, Danio rerio (family Cyprinidae), is an important vertebrate model system in many areas of biological research. Zebrafish are native to freshwater streams and rice paddies in the Ganges River of eastern India, Bangladesh, and Burma, where they are likely exposed to many naturally occurring organic substances (Mcclure et al. 2006; Spence et al. 2006). Environmental effects reported from many of the rice-producing countries include soil degradation, water contamination with nitrogen, eutrophication, and increased ammonia and other nitrogen trace gas emissions ( $\mathrm{Li} \underline{1995}$; Robertson et al. 2000). Additionally, from 1980 to 2000, use of synthetic nitrogen fertilizers in East Asian riceproducing nations has increased from approximately 4 to $10 \mathrm{Tg}$ [Food and Agricultural Organization (FAO) 2002] as part of a transition from more traditional to industrialized, broad-scale rice production. As zebrafish use chemical communication in the context of reproductive suppression and stimulation (Van den Hurk et al. 1987; Delaney et al. 2002; Gerlach 2006) and kin recognition (Mann et al. 2003; Gerlach and Lysiak 2006), the chemical environment is likely to affect transmission and reception of chemical stimuli. In this study, we investigated the ability of adult $D$. rerio to discriminate between 
conspecific and heterospecific chemical cues in the presence and absence of HA, as well as their habitat preferences for water with and without HA.

\section{Methods and Materials}

Animal Care and Housing We tested wild-type adult zebrafish that were raised together in the zebrafish facility at the Marine Biological Laboratory, Woods Hole, MA, USA. Fish were housed in an Aquatic Habitats tank system with a 14 L:10 D cycle and were fed twice daily with dry fish pellets and live Artemia salina nauplii. We used adult zebrafish from the $\mathrm{F}_{1}$ generation of wild-type individuals that originated from several pet shops and breeding centers in the USA, with the objective of obtaining out-crossed strains with higher genetic variability than fish from the same source.

Choice Tests Trials were performed in a choice flume (Fig. 1) powered by a peristaltic pump. The flume allows a laminar flow separation of two water stimuli (Atema et al. 2002; Mann et al. 2003; Gerlach and Lysiak 2006). The water height was maintained at approximately $1.5 \mathrm{~cm}$, and uniform unidirectional flow was maintained at a constant rate of $106 \mathrm{ml} / \mathrm{min}$ or $6.2 \mathrm{~cm} / \mathrm{s}$ ). Dye tests were conducted to confirm proper separation of the two different water flows.

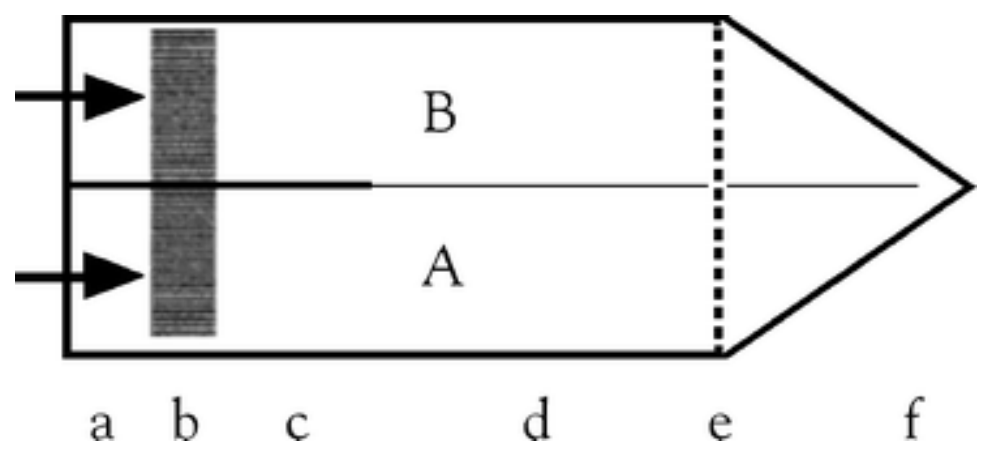

Fig. 1 Diagram of the choice flume. a Water inflow area, $\mathbf{b}$ collimator to homogenize turbulent flow, c barrier-separated channels, $\mathbf{d}$ area of flume where water columns remain separated (fine dotted center line), e screen to contain test subjects, and $\mathbf{f}$ outflow channel. $A$ The left side of the flume and $B$ the right side of the flume, when oriented toward the start of the flow. The dimensions of the flume are $33.6 \times 7.1 \times 6.5 \mathrm{~cm}$ (after Mann et al. 2003)

During odor choice tests, a single test fish was placed into the flume to acclimatize for $5 \mathrm{~min}$ before measurements began. The test consisted of two 5 min periods where odor stimuli were presented on alternate sides of the flume to control for possible side bias of the fish. After the first 5-min, another 1-min acclimation time was allowed when stimuli were alternated in the flume, and the test continued for another $5 \mathrm{~min}$. From position records taken every $10 \mathrm{~s}$, we 
calculated how often each fish selected a given stimulus. Water association time is widely used as a measure of preference in studies of kin recognition, shoaling preferences, and mate choice in laboratory studies on zebrafish (Rosenthal and Ryan 2005; Gerlach and Lysiak 2006; Gerlach et al. 2007) and poeciliids, including swordtails (see Wong and Rosenthal 2005 and references therein). We calculated the difference between the total number of observations in which a test fish was in the lane of the flume associated stimulus A or B, and tested whether that difference was significant from zero by using the Wilcoxon matched-pairs signed-ranks (WSR) test. If the fish did not have a preference for one of the odor stimuli or was unable to detect a difference between them, we would expect a random distribution on either side of the flume, which would result in no (zero) difference in distribution frequency between treatments. A nonparametric Van der Waerden chi-squared test was used to analyze differences between experiments (discussed below). Analyses were performed with SAS 3.1 software (SAS Institute).

We performed three sets of tests. First, we tested the response of male and female zebrafish to untreated water (dechlorinated tap water, $\mathrm{pH}$ 7.0) vs water containing $200 \mathrm{mg} / \mathrm{l}$ supplemental HA. Second, we presented female zebrafish with water containing conspecific cues vs water containing heterospecific cues (goldfish, Carassius auratus). Heterospecific water was created by isolating one goldfish with a body mass of approximately $35 \mathrm{~g}$ to a standing tank of untreated water. Conspecific water was made by isolating a single male zebrafish with a body mass of approximately $1 \mathrm{~g}$ to a separate standing tank. Tanks were filled with the same volume of untreated water ( $7 \mathrm{l}$ ) with airstone aeration $24 \mathrm{~h}$ before being used in the flume experiments. The heterospecific water was then diluted 35 times in untreated water to correct for body mass difference between the goldfish and the zebrafish. Third, we repeated the second set of experiments, this time treating both conspecific and heterospecific water stimuli with HA (Fluka cat. \#53680) for a final concentration of $200 \mathrm{mg} / \mathrm{l} \mathrm{HA}$ (Fisher et al. 2006). Several workers, including Malcolm and Mccarthy (1986) have pointed out differences between commercial humic acids, like the ones used in the present study, and HA derived from natural sources. Specifically, commercial HA have considerably higher carbon-to-nitrogen ratios and high ash contents (Malcolm and Mccarthy 1986). These factors are unlikely to fundamentally affect the behavior of HA with respect to chelating chemical signals or acting as antagonists to chemoreceptors.

To prepare HA-treated water, we measured $200 \mathrm{mg}$ of HA and placed the amount in a 1,000-ml volumetric flask. The flask was filled with $500 \mathrm{ml}$ of untreated water, magnetically stirred for about $15 \mathrm{~min}$, and the final volume was brought up to $1,000 \mathrm{ml}$. The mixture was transferred to a bottle that was capped and shaken vigorously for $5 \mathrm{~min}$, then set aside for $1-2 \mathrm{~h}$ before being used. The solution was shaken thoroughly once more before being used in flume trials.

\section{Results}


In odor choice tests that assayed habitat preference, zebrafish associated more with untreated water over HA-treated water (WSR test, $\mathrm{z}=59, \mathrm{~N}=19, \mathrm{P}=0.015$; Fig. 2).

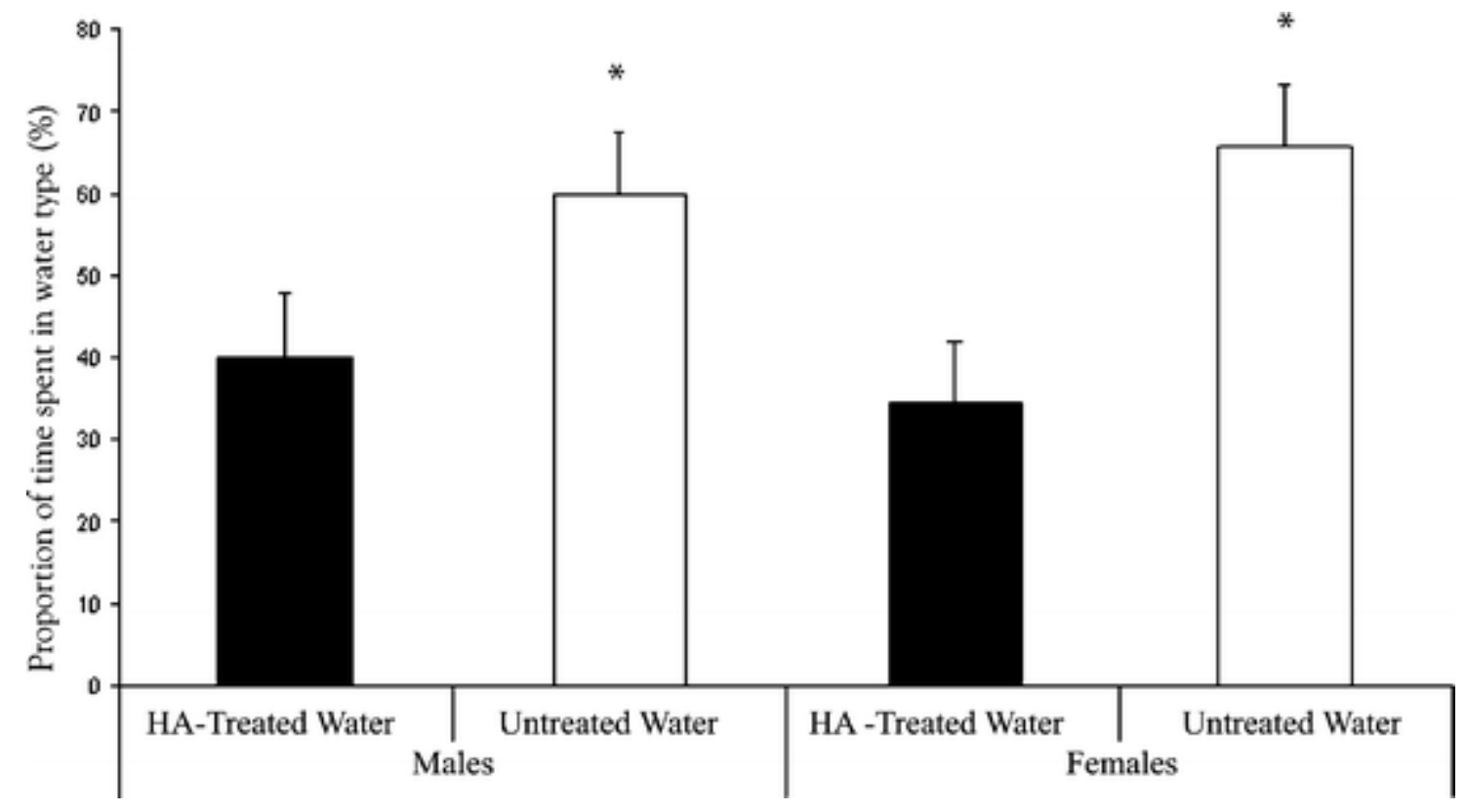

Fig. 2 Response (mean $\pm \mathrm{SE}$ ) of zebrafish to untreated water vs. water containing supplemental HA. Error bars indicate the standard error of means, and an asterisk above a column indicates a significant difference between untreated water and HA-treated water $(* P<0.02)$.

Female zebrafish tested in water without supplemental HA preferentially associated with conspecific cues over heterospecific cues (WSR test, $\mathrm{z}=162.5, \mathrm{~N}=25, \mathrm{P}<0.001$; Fig. 3 ). When $200 \mathrm{mg} / \mathrm{l} \mathrm{HA}$ were added to stimuli containing conspecific and heterospecific odor cues, zebrafish failed to show a preference $(z=63, n=25, P=0.09$; Figure 3$)$. The observed association for conspecific cues was significantly reduced in water containing supplemental HA. Zebrafish spent $82 \pm 3 \%$ of the observation time in proximity to conspecific odor stimulus in water without supplemental HA, but when tested in HAtreated water, they associated $44 \pm 3 \%$ of the trial with the conspecific odor cue (van der Waerden test, $\chi^{2}=26.3, d f=1, P<0.001$; Fig. $\underline{3}$ ). 


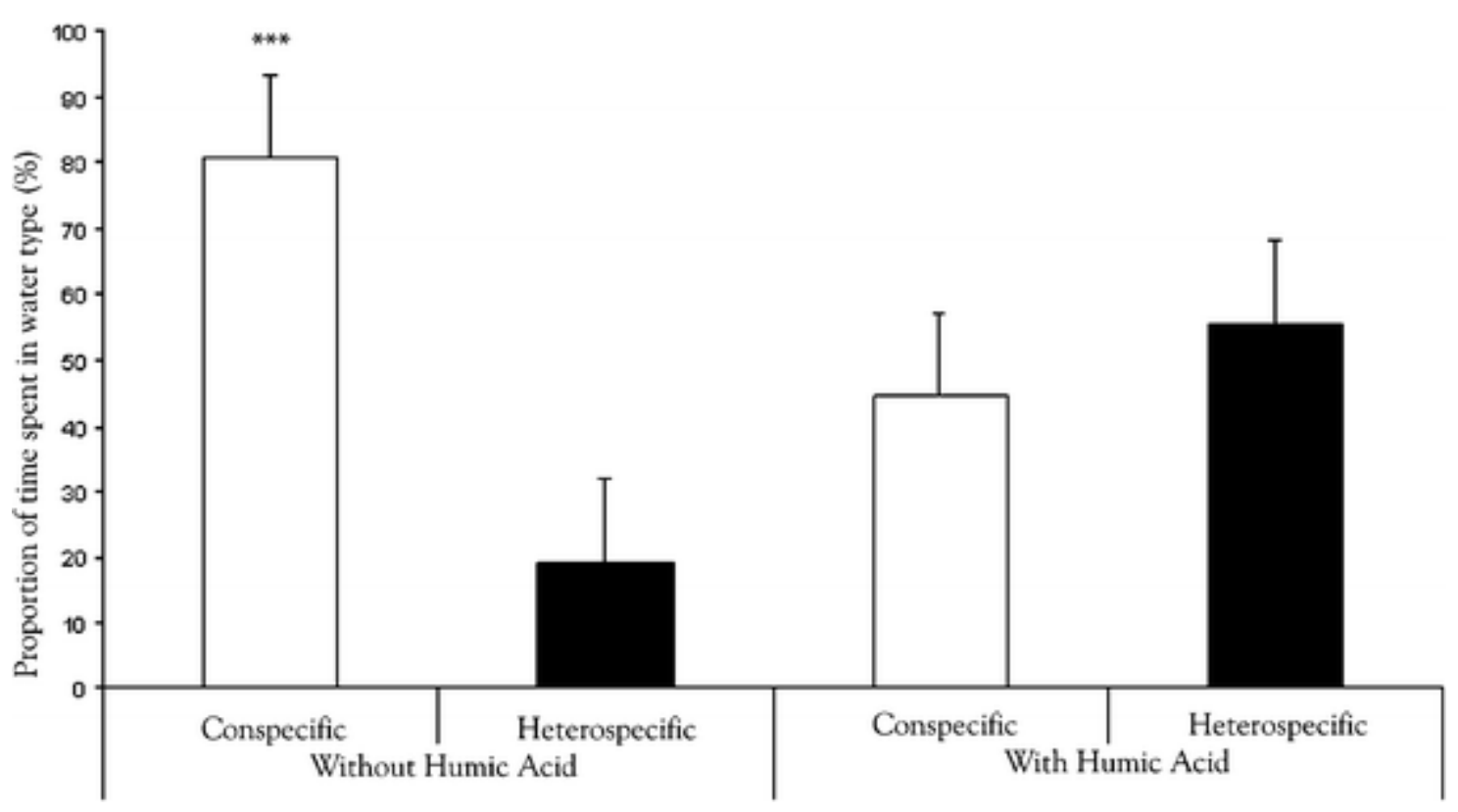

Fig. 3. Preference of female zebrafish (mean \pm SE) for conspecific (black) vs. heterospecific (white) stimuli in water with and without $200 \mathrm{mg} / \mathrm{l} \mathrm{HA}$. Error bars indicate standard error of means, and an asterisk above a column indicates a significant difference between association with conspecific and heterospecific cues in untreated water $(* * * P<0.001)$.

\section{Discussion}

Our results suggest that humic acid can interfere with recognition of conspecific chemical cues in zebrafish. While zebrafish showed a strong association with olfactory cues of conspecifics vs heterospecifics, they did not differentiate between these odor cues when tested in conditions with elevated levels of HA. These findings suggest that humic acid either reduces zebrafish preference for conspecific cues or reduces their avoidance from heterospecific cues. Our experimental design, however, does not allow us to discriminate between these two hypotheses; nevertheless, the biological significance is the same in either case: Humic acid alters zebrafish behavior toward chemical cues.

Elevated levels of HA in the environment as a byproduct of anthropogenic disturbance could potentially lead to misidentification of shoalmates and hybridization (Fisher et al. 2006). Zebrafish are sympatric with other danionin fishes over part of their range (Mcclure et al. 2006) and shoal assortatively with respect to species-typical visual cues (Engeszer et al. 2004; Rosenthal and Ryan 2005). The olfactory channel may be critical in social communication, particularly, when transmission of visual information is poor (Rosenthal and Lobel 2006). 
Chemical cues may also influence habitat choice. Zebrafish strongly avoided water containing HA in favor of clean water. The chemical environment may be an important determinant of habitat choice. Given the physiological (Yang et al. 2002; Steinberg et al. 2004) and sensory (Fisher et al. 2006) costs of HA exposure, selection may favor individuals who actively avoid high HA concentrations. These findings have important implications for species living in aquatic habitats with high levels of pollutants and agricultural runoff. In response to such environmental disturbances, many organisms may avoid areas important for survival, such as foraging areas and mating grounds (Sprague 1962; Geckler et al. 1976). High HA concentrations may drive organisms into suboptimal but less polluted habitats.

Several studies have demonstrated the deleterious effect of HA on a variety of organisms. High levels of HA in a natural habitat may have effects on multiple physiological and behavioral functions. HA can decrease olfactory response to pheromones in goldfish (Carassius auratus) and prevent pheromones from binding properly to chemoreceptors (Hubbard et al. 2002; Mesquita et al. 2003). Most known fish sexual pheromones are either steroids or prostaglandins (Stacey et al. 2003; Yambe et al. 2006), and their hydrophobic properties may make them more susceptible to HA binding. It remains to be seen how olfactory communication is maintained in fish that live in areas with naturally high concentrations of HA (Rosenthal and Lobel 2000).

Acknowledgment We thank Jelle Atema, Carley Schacter, and Michelle Gaona for the discussion and advice.

\section{REFERENCES}

ATEMA, J., KINGSFORD, J. M., and GERLACH, G. 2002. Larval reef fish could use odour for detection, retention and orientation to reefs. Mar. Ecol. Prog. Ser. 241:151-160.

ATIYEH, R. M., LEE, S., EDWARDS, C. A., ARANCON, N. Q., and METZGER, J. D. 2002. The influence of humic acids derived from earthworm-processed organic wastes on plant growth. Bioresour. Technol. 84:7-14.

DELANEY M., FOLLET C., RYAN N., HANNEY N., LUSK-YABLICK J., and GERLACH, G. 2002. Social interaction and distribution of female zebrafish (Danio rerio) in a large aquarium. Biol. Bull. 203:240-241. 
ENGESZER, R. E., RYAN, M. J. and PARICHY, D. M. 2004. Learned social preference in zebrafish. Curr. Biol. 14, 881-884.

FISHER, H.S., WONG, B. B. M., and ROSENTHAL, G. G. 2006. Alteration of the chemical environment disrupts communication in a freshwater fish. Proc. Roy. Soc. Lond. Biol. Sci. 273:1187-1193.

FOOD AND AGRICULTURE ORGANIZATION. 2002. FAOSTAT, Rome. $<$ http://apps.fao.org $>$

GERLACH, G., ATEMA, J., KINGSFORD, M.K., BLACK, K.P., and MILLER-SIMS, V. 2007. Smelling home can prevent dispersal of reef fish larvae. Proc. Natl. Acad. Sci. U.S.A., 104, 858-863.

GERLACH, G. 2006. Pheromonal regulation of reproductive success in female zebrafish: female suppression and male enhancement. Anim. Behav. 72:1119-1124.

GERLACH, G. and LYSIAK, N. 2006. Kin recognition and inbreeding avoidance in zebrafish is based on phenotype matching. Anim. Behav. 71:1371-1377.

GECKLER J. R., HORNING, W. B., NEIHEISEL, T.M., PICKERING, Q. H., ROBINSON, E. L., and STEPHEN, C. E. 1976. Validity of laboratory tests for predicting copper toxicity in streams. Ecological Research Series, USEPA-600/3-76-116, U.S. Environmental Protection Agency, Duluth no. 192.

HUBBARD, P. C., BARATA, E. N., and CANARIO, A. V. 2002. Possible disruption of pheromonal communication by humic acid in the goldfish, Carassius auratus. Aquat. Toxicol. 60:169-183.

KAPPLER, A. and HADERLEIN, S. B. 2003. Natural organic matter as reductant for chlorinated aliphatic pollutants. Environ. Sci. Technol. 37:2714-2719.

LI, C. 1995. Impact of agricultural practices on soil C storage and N2O emissions in 6 states in the US, in Soil Management and Greenhouse Effect, edited by R. Lai, J. Kimball, E. Levine, B.A. Stewart ., pp. 101- 112, CRC, Boca Raton, Fla.

MALCOLM R.L., and MCCARTHY P. 1986. Limitations in the Use of Commercial Humic Acids in Water and Soil Research. Environ. Sci. Technol. 20: 904-911.

MANN K. D., TURNELL E. R., ATEMA J., and GERLACH G. 2003. Kin Recognition in Juvenile Zebrafish (Danio rerio) Based on Olfactory Cues. Biol. Bull. 205:224-225.

MCCLURE, M. M., MCINTYRE, P. B., and MCCUNE, A. R. 2006. Notes on the natural diet and habitat of eight danionin fishes, including the zebrafish Danio rerio. J. Fish Bio. 69:553-570. 
MESQUITA, R., CANÁRIO, A. V. M., and MELO, E. 2003. Partition of Fish Pheromones between Water and Aggregates of Humic Acids. Consequences for Sexual Signaling Environ. Sci. Technol. 37(4): 742-746.

MOORE, P. A. and GRILLS, J. L. 1999. Chemical orientation to food by the crayfish Orconectes rusticus: influence of hydrodynamics. Anim. Behav. 58:953-963.

ROBERTSON, G. P., PAUL, E. A., and HARWOOD, R. R. 2000. Greenhouse gases in intensive agriculture: Contributions of individual gases to the radiative forcing of the atmosphere. Science 289: 1922-1925.

ROSENTHAL, G. G. and Lobel, P. 2006. Communication. In Behaviour and Physiology of Fish (vol. 24), K. Sloman, S. Balshine, R. Wilson eds. (Academic Press), 39-78.

ROSENTHAL, G. G. and RYAN, M. J. 2005. Assortative preferences for stripe patterns in danios. Anim. Behav. 70:1063-1066.

RUSSELL, S. T., KELLEY, J. L., GRAVES, J. A., and MAGURRAN, A. E. 2004. Kin structure and shoal composition dynamics in the guppy, Poecilia reticulate. Oikos 106:520-526.

SEEHHAUSEN, O., VAN ALPHEN, J.J.M., and WITTE, F. 1997. Cichlid Fish

Diversity Threatened by Eutrophication That Curbs Sexual Selection. Science 277:18081811.

SLABBEKOORN, H., PEET, M. Birds sing at a higher pitch in urban noise. Nature 464:267.

SPENCE, R., FATEMA, M. K., REICHARD, M., HUQ, K. A., WAHAB, M. A., AHMED, Z. F., and SMITH, C. R. 2006. The distribution and habitat preferences of the zebrafish in Bangladesh. J. Fish Bio. 69:1-14.

SPRAGUE, J. B. 1962. Effects of sublethal zinc and copper on migration of Atlanic salmon. U.S. Public Health Service Publication. Washington, D.C, No. 999-WP-25.

STACEY N., CHOJNACKI, A., NARAYANAN, A., COLE, T., and MURPHY, C. 2003. Hormonally derived sex pheromones in fish: exogenous cues and signals from gonad to brain. Can. J. Physiol. Pharmacol. 81(4):329-341.

STEINBERG., C. E. W., HO, S., KLOAS, W., LUTZ, I., MEINELT, T., PFLUGMACHER, S., and WIEGAND C. 2004. Hormonelike Effects of Humic Substances on Fish, Amphibians, and Invertebrates. Environ. Toxicol. 19:409-411.

STEINBERG, C. E. W. and MÜNSTER, U. 1985. Geochemistry and ecological role of humic substances in lakewater. In: G. R. Aiken, D. M. McKnight, R. L. Wershaw and P. 
MacCarthy (eds.), Humic Substances in Soil, Sediment, and Water, Wiley, New York: $433-455$.

THOMAS, J. D. 1997. The role of dissolved organic matter, particularly free amino acids and humic substances, in freshwater ecosystems. Freshw. Biol. 38:1-36.

THOMAS, J. D. and EATON, P. 1996. The spatio-temporal patterns and ecological significance of free amino acids and humic substances in contrasting oligotrophic and eutrophic freshwater ecosystems. Hydrobiologia 332:183-211.

WETZEL, R. G. 2001. Limnology. Lake and River Ecosystems. $3^{\text {rd }}$ ed. Academic Press, San Diego.

WOLF, M. C., and MOORE, P. A. 2002. Effects of the herbicide metolachlor on the perception of chemical stimuli by Orconectes rusticus. Journal of the North American Benthological Society 21 (3): 457-467.

WONG, B. B. M. and ROSENTHAL, G. G. 2005. Shoal Choice in Swordtails when Preferences Conflict. Ethology 111:179-186.

VAN DEN HURK, R., SCHOONENEN W. G. E. J., ZOELEN, G. A.V., and LAMBERT, J. G. D. 1987. The biosynthesis of steroid glucuronides in the testis of the zebrafish, Brachydanio rerio, and their pheromonal function as ovulation inducers. Gen. Comp. Endocrinol. 68:179-188.

YAMBE, H., KITAMURA, S., KAMIO, M., YAMADA, M., MATSUNAGA, S., FUSETANI, N., and YAMAZAKI, F 2006. L-Kynurenine, an amino acid identified as a sex pheromone in the urine of ovulated female masu salmon. PNAS 103;15370-15374.

YANG, M. L., HUANG, T. S., LEE, Y., CHEN, T. H., CHEN, S. Y., and LU, F. J. 2002. Inhibition of endogenous thyroid hormone receptor-beta and peroxisome proliferatoractivated receptor-alpha activities by humic acid in a human-derived liver cell line. Thyroid 12:361-371. 